\title{
EXPLORING THE SOCIAL LEARNING VALUE ENABLED BY AFFORDANCES OF THE FOOD FOR US MOBILE APPLICATION: THE STORY OF A SOUTH AFRICAN FOOD REDISTRIBUTION APP
}

\author{
Sarah Jane Durr and Heila Lotz-Sistika ${ }^{1}$ \\ Rhodes University, Grahamstown, South Africa \\ ${ }^{1}$ Professor
}

\begin{abstract}
This paper reviews the research undertaken in a social learning and innovation project focusing on food surplus redistribution, via a mobile application project called 'Food for Us'. This initiative was pilot tested in two study sites, namely Worcester, Western Cape and the Raymond Mhlaba municipality, Eastern Cape in South Africa. In South Africa, one-third of the food produced for consumption is wasted, whilst $26 \%$ of all households' experience hunger. Food surplus occurs in many contexts, including communities of emerging small-scale farmers, many of which aren't able to find markets for their products resulting in wastage. In a time of mobile technology expansion, the wide infiltration of internet-enabled smartphones into diverse communities has increased dramatically with the uptake of mobile applications being a key area of interest amongst environmental educators. The Food for Us application project aims to address the challenges of food insecurity and market access for small-scale farmers by creating an innovative technological solution in the form of a mobile application. The Food for Us mobile application and social learning research project aimed to investigate the social learning that was enabled within the communities of practice that utilized and interacted with the Food for Us mobile application. The Food for Us mobile application aimed to reduce on-farm food surplus by providing a tool on which small-scale farmer could find alternative markets for their unsold produce. This paper will look at the key findings that emerged out of the first phase of the project including the important social learning findings; instances of boundary crossing and intergenerational learning and network building, as well as the recommendations that have emerged that surround the need to develop strong social networked systems around technological innovative solutions to promote the realization of transformative value.
\end{abstract}

\section{KEYWORDS}

Informal Mobile Learning, Social Learning, Small-scale Farming, Transforming Food Systems, Market Transformation

\section{UNDERSTANDING THE FOOD WASTE / FOOD SECURITY PARADOX AND THE NEED FOR THE FOOD FOR US APPLICATION}

Food waste has become a major global and national concern, with one-third of all produce grown for human consumption being wasted, often ending up in landfills (FAO 2011). This excessive food waste is juxtaposed against a backdrop of mass malnutrition and hunger in many developing counties. According to the 2014 Food and Agriculture Organization (FAO) statistics yearbook, 24,8 \% of people in Africa are undernourished (FAO, 2014), yet it is believed that up to $37 \%$ or $120-170 \mathrm{~kg} /$ year per capita of food is wasted in sub-Saharan Africa (Sheahan \& Barrett, 2017). While South Africa produces enough food for its 53 million citizens, roughly $26 \%$ of South African households are food insecure (von Bormann, 2017). This wastage predominantly occurs in the agricultural production part of the agricultural value chain with 2.7 million tons of good food lost a year (Oelofse, 2015).

The research on food waste in South African food systems is very limited, with even less being conducted on the presence of food waste in the rural farming communities (Pereira, 2014). Khapayi and Celliers (2016) and Mpandeli and Maponya (2014) note that one of the key challenges that hinder small scale emerging farmer's development in South Africa is their lack of participation in appropriate local markets, therefore, 
resulting in wasted produce and resources. In a study conducted in King William's Town in the Eastern Cape, South Africa, it was found that $55 \%$ of the small-scale emerging farmers had no access to market information, therefore no exposure to new markets, prices, or information regarding produce supply and demand (Khapayi \& Celliers, 2016). Many farmers complained that their produce would be spoiled due to the lack of markets in close proximity (Khapayi \& Celliers, 2016).

This issue of food waste and lack in market access is occurring in a time of increased use of and a surge in ownership of Internet-enabled mobile phones in the postmillennial decade (Donner, Gitau, and Marsden 2011). Donner et al. (2011) argue that a mobile phone's portability, flexibility and ability to be personalized has the potential to increase productivity and agency within the global south, offering great opportunities for services to reach critical masses (Brown et al. 2003). In a recent national survey, 53\% of households had at least one member who had access to the Internet with more than a third of this, $(33,7 \%)$ being through mobile devices (Statistics South Africa, 2016). According to the Mobile Economy Sub-Saharan Africa 2017 report, there were 420 million unique mobile subscriptions, which translated into $43 \%$ mobile subscription penetration in Sub-Saharan Africa (GSMA 2017). Of these unique mobile subscriptions, a quarter is smartphone connections which enable the mobile phone user to access the internet (GSMA 2017). With the surge in internet use on internet-enabled mobile phones (smartphones), there has been an increase in the use of Application-Based Mobile Services, commonly known as mobile apps (Opera 2016). According to the 2016 State of the Mobile Web Report, South Africa is the leading African country in terms of application use with one-third of the population using applications regularly (Opera 2016). Aker and Mbiti (2010) note that recent app developments are designed to make life easier and more efficient (Aker \& Mbiti, 2010). Yet not much is known about the social learning associated with the uptake and use of these applications.

The Food for Us project, funded by the United Nations Environmental Programme (UNEP) under the 10-year framework of programs (10-YFP) One Planet initiative, aimed to trial a mobile application as a solution to divert surplus food to feed an alternative market whilst also looking to transform market access and strengthen the development of local circular economies via social learning. As such, the Food for Us project also aims to encourage the establishment of a community of learning around food waste and technological innovation to strengthen the research in these fields within the small-scale farming context (Jenkin, 2016). This paper looks at the type of social learning that emerged from the affordances of the Food for Us mobile application and the Food for Us support systems and makes recommendations on how social learning can be improved.

\section{FOOD FOR US FOOD REDISTRIBUTION APPLICATION PILOT}

The first phase of the Food for Us project ran over an 18-month period with the Food for Us application being trialed in two case study sites, Worcester, in the Western Cape province and Raymond Mhlaba Municipality in the Eastern Cape province of South Africa (Food for Us 2018a). This paper will be discussing the findings that emerged out of the Raymond Mhlaba, Eastern Cape case study.

The Raymond Mhlaba Municipality is a rural municipality within the Eastern Cape Province of South Africa. This municipality is a predominantly rural municipality with $72 \%$ of the population living in rural villages and on smallholder farms (Raymond Mhlaba Municipality 2017). The municipality has a high unemployment rate (87\%) (Raymond Mhlaba Municipality 2017) and high poverty rate with $64.7 \%$ of the population living in poverty (ECSECC 2017). The local government has highlighted the need to create jobs with potential being recognized in the local farming sector (Raymond Mhlaba Municipality 2017). It was within this context that we introduced the Food for Us application as an innovative project to assist in the empowerment of local farmers and the development of more connected supply chains.

The project started with a set of introductory workshops (August 2017) inviting a diverse set of stakeholders (farmers, retailers, government representatives amongst others) in the two case study sites to be part of a collaborative application designing process. The first version of the application, built off the suggestions that were made at the workshops, was made available to trial participants in mid-September 2017. The introduction of the Food for Us application was coupled with important training workshops that were run in both study sites to assist users on how to download, register and use the new application. In conjunction with the training, a support WhatsApp group was developed for the Eastern Cape case study to 
provide a support platform for users to discuss challenges, to navigate solutions and communicate with diverse stakeholders about available and demanded produce.

Within the Eastern Cape case study, the Food for Us project partnered with a similar social learning research project situated in the area, Amanzi for Food (Pesanayi, 2018). The Food for Us project was incorporated into the Amanzi for Food Training of Trainers course, which enabled the Food for Us project to reach more people and be exposed to more comments and suggestion. The Food for Us application was workshopped on three occasions within the Amanzi for Food course which was held in November 2017, February 2018 and May 2018

The final intervention that occurred in the Eastern Cape case study was the \#MatchMaking event, which took place in April 2018. This event invited local farmers and buyers in the community to come together for a day of networking and discussion between the members of the local supply chain. The event provided an opportunity for local buyers, sellers and intermediary stakeholders to network, build partnerships and come together to discuss supply chain challenges and potential solutions.

The first phase of the Food for Us project ended with a dissemination event, which was held at the Sustainability Institute in Stellenbosch, Western Cape. This event invited a diversity of stakeholders from the South African food system and food waste fields to join together to open discussion about innovative solutions (Food for Us 2018b). The dissemination event provided a space for the Food for Us project findings, from the Western Cape and Eastern Cape case study, to be presented and discussed therefore opening a platform for discussion and collaboration on how to address food waste in the current South African context (Food for Us 2018b).

A number of data sources was used to understanding how the Food for Us application value creation, and Food for Us social networked support systems and social learning were used within the Eastern Cape case study. The pilot trials included the trialing of 40 users use of the Food for Us application, 20 in the Western Cape province case study and 20 in the Eastern Cape Case study. The trial users included a mix of small-scale farmers, small-scale buyers, restaurant owners, and intermediaries' organization (who assist in the connecting of farmers and buyers). The data that was collected from the willing volunteer trial participants included;

1. Application metadata collected from the backend of the Food for Us application recording the activity on the application,

2. Baseline survey collected at the beginning of the project to get an understanding of the background of the trial participants, (23 collected in Eastern Cape case study)

3. Value creation semi-structured interviews to understand the experiences and value created, or lack thereof experienced by the several users, ( 6 value creation interviews)

4. WhatsApp group conversations and interactions around the Food for Us project, including reporting of issues challenges and opportunities,

5. Workshop discussions and observation

6. Final Survey conducted at the end of the project as a way to understand the type of value enabled and determine whether expectation was met and how best to learn from the project. ( 16 collected in the Eastern Cape Case study)

Through the data collected we identified the affordances that emerged from the Food for Us application and the Food for Us networked social learning processes. Simply put, an affordance is described as an action possibility (Turner 2005) however Doering, Miller, and Veletsianos (2002) explain that it is important to emphasize the relationship that exists between the user and artifact as the perception of an affordance, applied affordance and realization of the affordance all are interlinked and dependent on one another. In this paper, we look at the types of affordances of the application and the networked support systems and how these affordances enabled social learning.

\section{RESULTS}

\subsection{Using the Value Creation Framework}

The social learning that emerged from the Food for Us project was analyzed through the use of Wenger, Trayner and de Laats (2011) Value Creation Framework. The Value Creation Framework provides a framework to understand the social learning that occurs within and between communities of practice (Cop) 
through understanding social learning as a series of value creation cycles that exist between the grounded, people's current experiences, and the aspirational narrative of a community or individual, what people hope to achieve through a social learning/ shared practice processes (Wenger, Trayner, and de Laat 2011). Wenger, Trayner and de Laat (2011) define 5 types of value; immediate, potential, applied, realized and reframing. These value cycles can exists independently but most often interlink and interact with one another to develop a value creation narrative which records the cycles of value that emerge over time (Wenger, Trayner, and de Laat 2011).

The framework acts as a methodological tool, guiding researchers on the type of indicators to look for, and an analytic tool, which assist the user to map the value across five value cycles (Wenger, Trayner, \& de Laat, 2011). The strength of Wenger, Trayner and de Laat's framework is that provides a structured way to understand the information shared, therefore, understanding the different value created while not removing it from its context (de Laat, Schreurs, and Nijland 2014).

In the results discussed below, I discuss the different cycles of value that were enabled by the use of the Food for Us application and the networked social learning processes that accompanied it.

\subsection{Limited Value Realization from the use of the Mobile Application Alone}

The Food for Us application was used by the 20 users that made by the Food for Us pilot trial. The application was opened up to anyone else how would like to be part of the project, however, these use and experience of the project were not tracked. In total the Raymond Mhalaba Food for Us pilot had 25 sellers of produce, 11 buyers of produce and 7 researchers registered on the Food for Us application. Over the duration of the project, ending in May 2018, 31 produce uploads were made from the registered participants. The uploads included a variety of livestock, spinach, potatoes, and other local produce. Of the 31 uploads, there was only one transaction made between the sellers and buyers on the application. The key perceived and applied affordances of the Food for Us application can be seen in Table 1 below.

Table 1. Table showing the perceived and applied affordances of the Food for Us application

\begin{tabular}{|c|c|c|}
\hline \multicolumn{2}{|c|}{ Perceived Affordances } & \multirow{3}{*}{$\begin{array}{l}\text { Applied Affordances } \\
\text { > Increased interaction with mobile technology } \\
\text { > Increase local audience for farmers to advertise to } \\
\text { > Buyers exposed to a number of local producers. } \\
\text { > The information required for selling the products was simplified } \\
\text { > Users able to be buyer or seller of produce }\end{array}$} \\
\hline $\begin{array}{l}\text { Bring local farmers } \\
\text { into the local } \\
\text { supply chain to } \\
\text { produce for local } \\
\text { retailers: }\end{array}$ & $\begin{array}{l}\text { > Increased access to more buyers } \\
\text { > Increased access to more local farmers } \\
\text { > Increased communication within local supply }\end{array}$ & \\
\hline $\begin{array}{c}\text { Improve logistics of } \\
\text { the local trade - } \\
\text { Transport/packaging }\end{array}$ & $\begin{array}{l}\text { > Reduce distance driven and share transportation costs } \\
\text { > Recording of data about the Farmers produce } \\
\text { > Improve immediacy of the supply chain } \\
\text { > Price Comparison Tool for buyers } \\
\text { > Improved price for Farmers } \\
\text { > Market Information } \\
\text { > Improve Quality of the produce } \\
\text { > Reduce wasted resources (water, seed, fertilizer, fuel etc.) }\end{array}$ & \\
\hline
\end{tabular}

The two over-arching perceived affordances where that the users perceived that the Food for Us application would enable them to (1) bring local farmers into the local supply chain and (2) improve the logistics of local trade allowing for a more efficient, economical and waste-free local supply system. The applied affordances included, (1) increased interaction with mobile technology, (2) increased local advertising, (3) increased exposure to local farmers, (4) simplified market information and lastly (5) users able to be both buyers and sellers of produce through the application. These affordances enabled value to be created which has been summarized in table 2 below.

Table 2. Table summarizing the value created through the use of the Food for Us application

\begin{tabular}{|c|c|c|c|c|}
\hline Immediate & Potential & Applied & Realized & Reframing \\
\hline Excitement & $\begin{array}{c}\text { Improve mobile Use } \\
\text { Skills }\end{array}$ & Download the application & $\begin{array}{c}\text { Increased mobile use } \\
\text { confidence }\end{array}$ & $\begin{array}{c}\text { Using technology as an agri-business } \\
\text { tool }\end{array}$ \\
\hline $\begin{array}{c}\text { Exposure to new } \\
\text { ideas }\end{array}$ & Build connections & $\begin{array}{c}\text { Advertise produce on the } \\
\text { application }\end{array}$ & Exposure to local produce & \\
\hline & $\begin{array}{c}\text { Share market } \\
\text { information }\end{array}$ & Search for demanded produce & & \\
\hline
\end{tabular}


As one can see from table 2 above, the majority of the value emerged as potential value and applied value, with little, realized and reframing value emerging from the applied affordances.

The immediate value that emerged included excitement and enthusiasm. There was much interest and excitement that developed out of the introduction of the Food for Us application with most of the users showing immediate enthusiasm about being part of the application trial. The second immediate value that emerged was exposure to new ideas, which included ideas of using mobile technology to increase a farmers market, as well engaging in ideas around food waste and wasted resources and how to address these challenges.

The potential value that emerged developed out of the excitement that surfaced as an immediate value. The potential value that emerged included; (1) improved skills around the use of mobile technology, (2) develop connections, and (3) share market information. Users improved their perceived ability to engage with mobile applications, which plays an important part in enabling action and therefore the development of further value creation cycles. Through engaging with the produce upload adverts on the application; users have started to connect with unknown farmers and buyers, therefore developing their social network further increasing the potential to further work with new people. Finally, the use of the Food for Us application shared information through allowing the uploads to be viewed by all who had the application, this provided farmers with some idea of what was being produced and sold and at what price. The potential value provided a foundation from which the applied value could draw on.

The applied value that emerged from the use of the application included all the actions that were taken including the users downloading the application (43 in total in the Eastern Cape case study), uploading of produce from the farmers (31 uploads in the Eastern Cape), searching the application for demanded produce and the viewing of the public wall ${ }^{1}$.

Not all of the applied actions where successful in their pursuit of the over-arching aspiration narrative (this being the shared aim of the project - to reduce on-farm food waste and wasted resources while increasing market access and assisting with the strengthening of local circular economies). The realized value that emerged included the increased confidence of users to use their mobile phones and applications. This was recorded in many of the value creation interviews where people explained that they felt they were more confident to use their phone in different ways that they had not engaged in before. The second realized value was that a number of the buyers explained that they were exposed to farmers whom they had not known prior to the Food for Us project. Unfortunately, there was only one transaction out of 31 uploads made on the application therefore not warranting the transacting of local produce on the application a success.

The final cycle of value is the reframing value that emerged through the duration of the project. Wenger, Trayner and de Laat (2011) explain reframing value as the transformation capital that emerges where the participants of the community start to reimagine success based on the previous cycles of value. The reframing value that emerged was that the trial users started to reframe how they imagined using technology as an effective tool for furthering their agricultural or consumer businesses. Through improving their skills (potential), applying their skills in the use of the application (applied) and becoming more confident in mobile technology use (realized), the users started to re-imagine what mobile technology could do for them.

As one can see there was value that emerged out of the use of the Food for Us application alone, however, this value was inhibited through a number of challenges including the inconsistent stability of the application, users access to compatible technology and the complex process of the application, to name just a few. Therefore, value creation from the direct use of Food for Us application was not fully realized to meet the expectations set out by the Food for Us project.

\subsection{Rich Value Creation enabled by the Networked Social Learning Processes that accompanied the Introduction of the Food for Us Application}

As described above, there were a number of networked social learning processes that accompanied the introduction of the Food for Us application in the Raymond Mhlaba case study. These included the Food for Us WhatsApp group, the application training workshops, the Food for Us workshops within the Amanzi for Food course, the \#MatchMaking event and the continuous research interaction. These networked social

\footnotetext{
${ }^{1}$ The public wall was a feature of the Food for Us application which provides a space for event notifications, recipe sharing and other miscellaneous to be recorded and shared with all the application users.
} 
learning processes evolved as the project went on, changing to accommodate and support the Food for Us users to get the most out of the application as they could. As was found with the Food for Us application, there were many perceived and applied affordances that emerged out of the networked social learning processes as well. These affordances can be seen in table 3 below;

Table 3. Showing the perceived and applied affordances of the various networked social learning processes that accompanied the introduction of the Food for Us application

\begin{tabular}{|c|c|c|c|}
\hline \multicolumn{2}{|c|}{ Perceived Affordances } & \multicolumn{2}{|r|}{ Applied Affordances } \\
\hline $\begin{array}{l}\text { Improve } \\
\text { Logistics }\end{array}$ & $\begin{array}{l}\text { > Create a consistent supply of } \\
\text { locally produced food } \\
\text { > Platform to discuss demanded } \\
\text { produce }\end{array}$ & $\begin{array}{l}\text { Network } \\
\text { Building: }\end{array}$ & $\begin{array}{l}\text { > Link Consumers to local producers } \\
\text { > Search for demanded produce }\end{array}$ \\
\hline $\begin{array}{l}\text { Developing } \\
\text { farmers skills }\end{array}$ & $\begin{array}{l}\text { > Business skills and recording } \\
\text { of data } \\
\text { > Local Pricing of produce }\end{array}$ & $\begin{array}{l}\text { Grow the Food } \\
\text { for Us } \\
\text { community }\end{array}$ & $\begin{array}{l}\text { > Enable local trading of produce } \\
\text { > Food for Us Community developed } \\
\text { > Bring the youth into the local } \\
\text { supply chain }\end{array}$ \\
\hline Partnership & $\begin{array}{l}\text { > Networking opportunity for } \\
\text { buyers and sellers of produce. } \\
\text { > Bringing new partners into } \\
\text { conversation }\end{array}$ & Communication & $\begin{array}{l}>\text { Communication between users } \\
\text { (Producers and consumers) } \\
>\text { Communication between the users } \\
\text { and app developers }\end{array}$ \\
\hline \multirow{5}{*}{$\begin{array}{l}\text { Partnership } \\
\text { Opportunity to } \\
\text { strengthen } \\
\text { local } \\
\text { businesses }\end{array}$} & \multirow{2}{*}{$\begin{array}{l}\text { > Networking opportunity } \\
\text { between the buyers and sellers } \\
\text { of produce. } \\
\text { > Bringing new people into the } \\
\text { conversation } \\
\text { > Market Access } \\
\text { > Incentivize farmers } \\
\text { > Reduce the transaction costs } \\
\text { of users }\end{array}$} & $\begin{array}{l}\text { Knowledge } \\
\text { Sharing }\end{array}$ & $\begin{array}{l}\text { > Recognize Food waste } \\
>\text { The shift toward organic crops and } \\
\text { sustainable farming practices }\end{array}$ \\
\hline & & $\begin{array}{l}\text { Support } \\
\text { Platform }\end{array}$ & $\begin{array}{l}\text { > Technical difficulties } \\
\text { > Experimenting with the } \\
\text { application } \\
\text { > Support New users } \\
\text { > Collaborative Troubleshooting }\end{array}$ \\
\hline & & Collaboration & $\begin{array}{l}\text { > Negotiation of how the app will be } \\
\text { used } \\
\text { > Supportive feedback loops } \\
\text { > Shared interest and Ownership of } \\
\text { the project }\end{array}$ \\
\hline & & $\begin{array}{l}\text { Building } \\
\text { Confidence: }\end{array}$ & $\begin{array}{l}\text { > Building Business and Marketing } \\
\text { skills } \\
\text { > Learn about IT }\end{array}$ \\
\hline & & $\begin{array}{l}\text { Strengthen } \\
\text { Local Supply } \\
\text { Chain: }\end{array}$ & $\begin{array}{l}\text { > Communication } \\
\text { > Building a circular economy } \\
\text { > Build a joint vision for local supply } \\
\text { chain } \\
\text { > Healthy competition } \\
\text { > Enable local trade }\end{array}$ \\
\hline
\end{tabular}

The number and complexity of affordances that is enabled by the networked social learning processes are much more extensive than those of the Food for Us application. However, it is important to note that here we are comparing the affordances of one tool within a multitude of social activities and workshops. The applied affordances allowed for actions that were instrumental in enabling value creation. The afforded communication between the trial participants (afforded by the Food for Us WhatsApp group) and the afforded building of relationships and extension of networks (afforded by the \#MatchMaking event, Training Workshops and Amanzi for Food Training of Trainers courses) enabled large amounts of value to be created as described in table 4 showing the value creation enabled by the networked social learning networks.

The value that emerged from the social learning support structures created a much richer and multi-leveled value for the Food for Us project. The most important value that emerged was the strengthening of the local supply chain through the development and opening up of social networks (realized value). Farmers who had not been part of existing farming networks were introduced into the network (such as youth co-operative members). There were instances of inter-generational learning where older members of 
the farming community shared knowledge accumulated through years of practical experience with the young farmers and newcomers There was also sharing of knowledge from the youth members who assisted elder Food for Us trial participants with downloading and utilizing the Food for Us application (potential value). There was also increased discussion between the different stakeholders within the local supply chain, therefore, enabling boundary crossing between different communities of practice (such as the small scale farmers and the local buying community). This intergenerational knowledge sharing and cross-community of practice boundary knowledge sharing was enabled by the support systems through their affordances to enable relationship building (potential value), building connections (potential value), encourage new channels of communication (applied value) and build a strong and supportive community (realized value) around the shared idea of strengthening a circular local supply chain.

Table 4. The value creation that emerged from the networked social learning processes that accompanied the introduction of the Food for Us application

\begin{tabular}{|c|c|c|c|c|}
\hline Immediate & Potential & Applied & Realized & Reframing \\
\hline Excitement & $\begin{array}{l}\text { Network \& } \\
\text { Relationship } \\
\text { Building }\end{array}$ & $\begin{array}{c}\text { Increased } \\
\text { communication }\end{array}$ & $\begin{array}{l}\text { Strengthening of local } \\
\text { supply chain }\end{array}$ & $\begin{array}{l}\text { Using technology as } \\
\text { an agri-business tool }\end{array}$ \\
\hline $\begin{array}{l}\text { Exposure to } \\
\text { new ideas }\end{array}$ & Data Base & Community Support & $\begin{array}{l}\text { Transacting of local } \\
\text { produce }\end{array}$ & $\begin{array}{c}\text { Definition of food } \\
\text { waste in rural areas }\end{array}$ \\
\hline \multirow[t]{5}{*}{ Build Contacts } & Sense of Community & $\begin{array}{l}\text { Collaborative } \\
\text { Troubleshooting }\end{array}$ & Improved application & $\begin{array}{l}\text { Bring youth into the } \\
\text { local supply chain }\end{array}$ \\
\hline & Building Skills & $\begin{array}{c}\text { Supportive Feedback } \\
\text { loops }\end{array}$ & $\begin{array}{l}\text { Ownership of the } \\
\text { project }\end{array}$ & $\begin{array}{l}\text { Importance of strong } \\
\text { social networks }\end{array}$ \\
\hline & WhatsApp Group & $\begin{array}{l}\text { Marketing and trading } \\
\text { of produce }\end{array}$ & $\begin{array}{l}\text { Increased confidence } \\
\text { in Mobile Use }\end{array}$ & \\
\hline & Knowledge Sharing & Recognize Food waste & & \\
\hline & & $\begin{array}{c}\text { Interest in Sustainable } \\
\text { Farming }\end{array}$ & & \\
\hline
\end{tabular}

The networked social learning systems also enabled improved use of the Food for Us application through enabling the users to encourage one another with supportive messages (applied value) on the WhatsApp group. The WhatsApp group invited all those who were part of the trial to be part of the WhatsApp group. The WhatsApp group also included the technical liaison for the Food for Us application and Food for Us trial managers. This enabled direct contact between the application users and the application technical team, which allowed for application errors to be reported and advised upon immediately (applied value). Through collaborative efforts, users and the technical liaisons were able to collectively identify a common error and report it to the coding team so that software issues were timeously solved (realized value). These supportive feedback loops enabled the coding team to develop a more stable and user-friendly application by the end of the 18-month project period.

As explained above, there was very limited transacting of produce that occurred on the Food for Us application itself, however, this was not the case in the networked social learning processes. According to the final survey data, there was between $15-20$ transactions made outside of the Food for Us application which was enabled by the Food for Us project. Many users explained that they would view the produce that was available on the Food for Us application and then contact the farmer outside of the application as a matter of convenience. This prompted the research team to try and understand why users did not feel comfortable communicating through the application and instead used familiar communicating channels such as calling or using WhatsApp. We realized that in future research, it is important to understand the technology use culture of the application audience, therefore understanding how the users engage and utilize mobile technology, so as to allow for contextualized application functionalities that speak to the used culture.

The technical support on the Food for Us WhatsApp group, the training workshops and \#MatchMaking event also enabled users to develop their skills in terms of using mobile technology. Not only did the training workshops show users the specifics of the Food for Us application, but also explored how to use email and 
social networking software (such as WhatsApp) to build social networks to develop one's business further. This emerged as one of the major cycles of reframing value that emerged from the Food for Us project, as users started to re-imagine how they could use technology, understanding that technology could act as an important tool to build social networks and encourage communication and collaboration in and across communities of practice.

The networked social learning processes, which supported the implementation of the Food for Us application in the Raymond Mhlaba community, enabled multiple levels of value creation within the project landscape, showing the importance of investing in social learning and network building in social systems of uptake and use around mobile application design and use.

\section{CONCLUSION}

In conclusion, as can be seen from the results summarized above, there was much learning that emerged from the Food for Us pilot project. Through the value creation analysis, it becomes clear that technical innovations on their own do not change situations. As Mc Namara (2003) explains, "ICTs enable change; they do not create it" (Mcnamara 2003, 6). What emerged, as a successful component of the project was the strong, networked social learning support structures that enabled connections, discussion and collaboration between the Food for Us trial users.

There were a number of limitations to the project, the key one being the length of the project. The 18-month period was too short to achieve a full understanding of the type of value created by the application and the networked-social learning processes over time. In future research, we recommend that such a project be conducted over a longer time frame with more time allocated to the development and refinement of the application.

Going forward, we are hoping to continue this research and explore what value is created through this project over a second phase of the Food for Us project. We hope to explore how best to support sustainable social innovation in multi-stakeholder partnerships through developing sustainable business models, and expanding the connections between buyers and sellers in local learning and transaction networks, as site for uptake and use of the mobile technology, where associated social learning potential can also be maximized.

\section{REFERENCES}

Brown, Irwin, Zaheeda Cajee, Douglas Davies, and Shaun Stroebel. 2003. "Cell Phone Banking: Predictors of Adoption in South Africa — an Exploratory Study.” International Journal of Information Management 23 (5): 381-94.

Donner, Jonathan, Shikoh Gitau, and Gary Marsden. 2011. "Exploring Mobile-Only Internet Use: Results of a Training Study in Urban South Africa." International Journal of Communication 5: 24.

ECSECC. 2017. "RAYMOND MHLABA LOCAL MUNICIPALITY SOCIO-ECONOMIC REVIEW AND Outlook, 2017." Vincent.

FAO. 2011. Food Waste Report. Rome. https://doi.org/10.1098/rstb.2010.0126.

Food for Us. 2018a. "Food For Us; Reducing Food Waste, Supporting Social Learning, Creating Value." Grahamstown.

. 2018b. "Workshop Synthesis." Stellenbosch.

GSMA. 2017. "The Mobile Economy Sub-Saharan Africa 2017." https://www.gsmaintelligence.com/research/?file=7bf3592e6d750144e58d9dcfac6adfab\&download.

Laat, Maarten de, Bieke Schreurs, and Femke Nijland. 2014. "Communities of Practice and Value Creation in Networks." In, 247-57. Routledge.

Mcnamara, Kerry S. 2003. "ICTs, Poverty and Development: Learning from Experience."

Opera. 2016. "State of the Mobile Web Africa 2016." https://blogs.opera.com/news/

wp-content/uploads/sites/2/2016/11/SMWAfrica-Opera-report-2016-01-WEB-1.pdf.

Pereira, Laura M. 2014. "The Future of South Africa's Food Systems: What Is Research Telling Us?”

Raymond Mhlaba Municipality. 2017. "Raymond Mhlaba Local Municipality 2017/ 2022 IDP.” Fort Beaufort.

Turner, Phil. 2005. "Affordance as Context." Interacting with Computers 17 (6): 787-800. https://doi.org/10.1016/j.intcom.2005.04.003.

Wenger, Etienne, Beverly Trayner, and Maarten de Laat. 2011. Promoting and Assessing Value Creation in Communities and Networks: A Conceptual Framework (April). Ruud de Moor Centrum. Vol. 18. http://www.open.ou.nl/rslmlt/Wenger_Trayner_DeLaat_Value_creation.pdf. 